\title{
Right ventricular involvement in acute myocardial infarction. Risk stratification by visualization of wall motion, edema and delayed enhancement cardiovascular magnetic resonance
}

\author{
Matthias Grothoff*, Christian Elpert, Janine Hoffmann, Suzanne de Waha, Ingo Eitel, Holger Thiele, \\ Matthias Gutberlet
}

From 2011 SCMR/Euro CMR Joint Scientific Sessions Nice, France. 3-6 February 2011

\section{Introduction}

Patients with RVI complicating AMI suffer from increased morbidity and mortality, but it is unclear which patients are in risk of developing RVI. Cardiovascular magnetic resonance (CMR) can identify patients with RVI and might add important information for risk stratification, prognosis and treatment.

\section{Purpose}

We aimed to determine the predictors of right ventricular involvement (RVI) assessed by wall motion abnormalities, edema, myocardial salvage and delayed enhancement in acute reperfused myocardial infarction (AMI) and the prognostic significance of RVI.

\section{Methods}

We studied 431 patients 1-4 days after primary angioplasty for ST-elevation AMI. T2-weighted and delayed enhancement (DE) CMR was used for visualizing edema and scar to calculate myocardial salvage (MS). Cine-imaging was used for wall motion analysis. Patients with RVI were compared to matched patients with isolated left ventricular (LV) infarction. The primary endpoint was the occurrence of a major adverse cardiac event (MACE): a composite of death, reinfarction and congestive heart failure.

\section{Results}

RVI with localized wall motion impairment and edema was found in 69 patients, of which 41 showed myocardial necrosis in DE imaging. In multivariate linear regression

University of Leipzig - Heart Center, Leipzig, Germany analysis predictors of RVI were a low TIMI-flow grade before angioplasty (OR 3.93, 95\%CI 1.16-13.29, $\mathrm{p}=0.03$ ), a high RV myocardial mass (OR 1.1, 95\% CI 1.01-1.20, $\mathrm{p}=0.03$ ) and a low ST segment resolution (OR 2.32, 95\% CI 1.06-5.05, $\mathrm{p}=0.03)$. In Cox regression the strongest predictor of MACE was RVI (HR 3.66, 95\%CI 1.99-5.66, $\mathrm{p}<0.001)$.

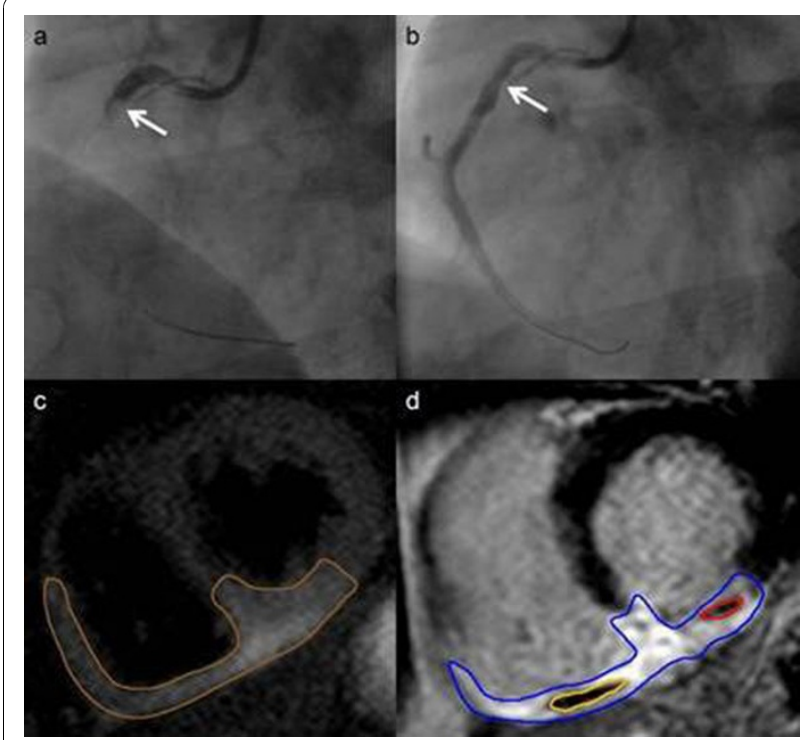

Figure 1 Coronary angiography and CMR of a severe inferior infarction: a proximal occlusion of the RCA, after $\mathrm{PCl} \mathbf{b}$ with post TIMI-flow II. Area at risk (brown contour) extends from the LV inferior wall to the interventricular septum and the RV inferior and free wall in c. In $\mathbf{d}$ MO of the RV (yellow contour) and the LV ( red contour) is shown. 


\section{Conclusions}

RVI detected by CMR is a strong and independent predictor of clinical outcome after acute reperfused AMI.

Published: 2 February 2011

doi:10.1186/1532-429X-13-S1-P116

Cite this article as: Grothoff et al:: Right ventricular involvement in acute

myocardial infarction. Risk stratification by visualization of wall motion,

edema and delayed enhancement cardiovascular magnetic resonance.

Journal of Cardiovascular Magnetic Resonance 2011 13(Suppl 1):P116.

Submit your next manuscript to BioMed Central and take full advantage of:

- Convenient online submission

- Thorough peer review

- No space constraints or color figure charges

- Immediate publication on acceptance

- Inclusion in PubMed, CAS, Scopus and Google Scholar

- Research which is freely available for redistribution

Submit your manuscript at 